\title{
AVALIAÇÃO DE DIFERENTES MÉTODOS DE CONSERVAÇÃO ESPLÊNICA PARA TRATAR LESÃO CORTANTE DO BAÇO EM CÃO
}

\author{
ASSESSMENT OF DIFFERENT CONSERVATIVE METHODS OF THE SPLEEN FOR \\ TREATMENT OF SPLENIC INCISIONAL LESION IN THE DOG
}

\author{
Andy Petroianu, TCBC-MG ${ }^{1}$; Thiago Costa Pereira ${ }^{2}$; \\ Teon Augusto Noronha de Oliveira $^{2}$; Alfredo José Afonso Barbosa
}

\begin{abstract}
RESUMO: Objetivo: A morbimortalidade do tratamento conservador do baço após trauma desse órgão depende da extensão da lesão e da experiência da equipe cirúrgica com trauma esplênico. O objetivo deste trabalho é avaliar experimentalmente a recuperação esplênica após lesão cortante tratada conservadoramente. Método: Foram utilizados 20 cães machos, mestiços, com peso variando entre $7 \mathrm{~kg}$ e $12 \mathrm{~kg}$. Sob anestesia com pentabarbitúrico sódico endovenoso, provocou-se uma lesão cortante longitudinal no baço, em uma extensão de $5 \mathrm{~cm}$ e profundidade de $3 \mathrm{~cm}$. Em seguida, os animais foram distribuídos aleatoriamente, de acordo com a conduta com a ferida esplênica, em três grupos: Grupo $1(n=10)$ - sem reparo cirúrgico; Grupo $2(n=5)$ - sutura esplênica contínua com fio de categute cromado 5-0; Grupo $3(\mathrm{n}=5)$ - introdução de um segmento de omento maior na ferida esplênica e sutura contínua do baço com o omento, utilizando fio categute cromado 5-0. Os cães foram acompanhados durante cinco (Grupo 1A) ou 28 (Grupo 1B, 2 e 3) dias. Resultados: Todos os animais sobreviveram ao pós-operatório e não foram percebidas adversidades decorrentes da operação durante esse período. Não foi encontrada diferença no aspecto macroscópico dos baços retirados de todos os grupos. À microscopia, percebeu-se fragmento de omento dentro da cicatriz esplênica nos animais do Grupo 3. Conclusão: A lesão cortante de baço canino pode ser tratada pelos métodos conservadores. Caso se opte pelo tratamento cirúrgico, a sutura com e sem auxílio do omento são eficazes (Rev. Col. Bras. Cir. 2004; 31(6): 364-367).
\end{abstract}

Descritores: Baço/Leões; Esplenectomia; Esplenectomia/métodos; Ferimentos e Lesões.

\section{INTRODUÇÃO}

A crescente incidência de traumas abdominais e a frequiência com que o baço é atingido conferem ao trauma esplênico destaque especial nos serviços de urgência, tendo em vista que esse é o órgão abdominal mais lesado no traumatismo contuso ${ }^{1-4}$.

Os avanços nos métodos propedêuticos, como lavagem peritoneal, ultra-sonografia, tomografia computadorizada, angiografia, cintilografia e laparoscopia permitem o planejamento melhor do tratamento ${ }^{2,3,5}$. Os procedimentos terapêuticos incluem desde o acompanhamento clínico, nas lesões menores, até a esplenectomia, quando o acometimento for mais extenso. Lamentavelmente, a maioria das feridas do baço ainda é tratada com a retirada completa do órgão, que é o maior reservatório de linfócitos do organismo e é responsável pela produção de opsoninas, como anticorpos, fatores do complemento e outros peptídeos ${ }^{2,6-9}$. A esplenectomia total pode facilitar a instalação de infecções graves, por vezes fulminantes, que podem ocorrer em até $4 \%$ dos doentes ${ }^{2,7-9}$. Essa adversidade é pior em crianças e pessoas imunodeprimidas, como os idosos e os portadores de doenças crônicas ${ }^{6,9}$. A fim de preservar a função esplênica e evitar as complicações da asplenia tem sido cada vez mais adotado o tratamento conservador ou as operações que con- servam o baço, entre as quais inclui-se a sutura, a esplenectomia parcial, a esplenectomia subtotal e os autoimplantes esplênico ${ }^{2,6,7,10-12}$. Quando há dificuldade em coibir o sangramento por meio de sutura, devido à consistência do parênquima do baço, tem-se optado pelo auxílio de tecidos vizinhos, como o omento maior e as próteses sintéticas ${ }^{1,9,13}$.

Apesar dos bons resultados com a utilização do retalho de omento maior na reparação esplênica, não encontramos referências sobre as repercussões dessa operação na cicatrização esplênica. Nesse sentido, o presente trabalho teve com objetivo comparar a recuperação morfológica do baço após esplenorrafia com ou sem omentoplastia e o não tratamento de lesão esplênica cortante, em modelo experimental.

\section{MÉTODO}

Este trabalho foi desenvolvido no Laboratório da Disciplina de Técnica Cirúrgica da Faculdade de Medicina (FM) da UFMG. O protocolo foi seguido de acordo com as normas internacionais para utilização de animais de experimentação (Office of Science and Health Reports) e iniciado após aprovação pela Comissão Científica e pelo Comitê de Ética do Hospital das Clínicas - MG.

Foram utilizados vinte cães machos, adultos, pesando entre 7 e $12 \mathrm{~kg}$, mantidos em gaiolas individuais para animais

1. Professor Titular do Departamento de Cirurgia da Faculdade de Medicina - UFMG; Docente Livre em Cirurgia da Faculdade de Medicina de Ribeirão Preto - USP; Docente Livre em Cirurgia da Escola Paulista de Medicina - UNIFESP; Doutor em Fisiologia e Farmacologia, Pesquisador IA do CNPq.

2. Acadêmico da Faculdade de Medicina da Universidade Federal de Minas Gerais

3. Professor Titular do Departamento de Anatomia Patológica da Faculdade de Medicina - UFMG 
de médio porte no Biotério da FM-UFMG. Os animais receberam alimento (ração para cães), bem como água à vontade e, anteriormente ao procedimento cirúrgico, foram acompanhados durante duas semanas, para observar o estado de saúde ${ }^{10}$.

As operações foram realizadas sob anestesia geral com pentabarbitúrico sódico endovenoso $(10 \mathrm{mg} / \mathrm{kg})$. Após tricotomia de todo o abdome, procedeu-se à antissepsia com solução alcoólica de iodo a $2 \%$. A cavidade abdominal foi aberta na linha mediana supra-umbilical. O baço foi mobilizado para o campo cirúrgico e, com o auxílio de uma lâmina de bisturi, realizou-se uma incisão longitudinal medindo $5 \mathrm{~cm}$ de comprimento e $3 \mathrm{~cm}$ de profundidade (Grau III pela AAST-1994). O procedimento operatório subseqüente dependeu do protocolo estabelecido para os animais, que foram divididos aleatoriamente em três grupos:

Grupo $1(\mathrm{n}=10)$ - a ferida esplênica não foi tratada e o sangramento esplênico não foi coibido; a cavidade abdominal foi fechada em dois planos com fio de náilon 3-0.

Grupo $2(n=5)$ - a ferida esplênica foi suturada com chuleio, utilizando fio de categute cromado 5-0, em seguida a cavidade abdominal foi fechada em dois planos com fio de náilon 3-0.

Grupo $3(n=5)$ - um segmento de omento maior foi introduzido dentro da lesão esplênica, que em seguida foi suturada com chuleio utilizando fio de categute cromado 5-0, que transfixou o baço e o omento. A cavidade abdominal foi fechada em dois planos com fio de náilon 3-0.

No pós-operatório, os cães do Grupo 1 foram divididos aleatoriamente em dois subgrupos $(n=5)$, conforme o tempo de acompanhamento: Subgrupo 1A - 5 dias e Subgrupo 1B - 28 dias. Os cães do Grupo 2 e do 3 foram acompanhados por 28 dias.

Ao fim do período de acompanhamento, os cães foram reoperados sob anestesia endovenosa, com pentabarbitúrico sódico. Após inventário de toda a cavidade abdominal, o baço foi retirado completamente, para avaliação macroscópica. Em seguida, para o estudo histopatológico, retirou-se uma fatia do segmento esplênico que continha a incisão ou a sutura que foi fixado em formaldeído a $4 \%$ durante um a dois dias. Após esse período, os fragmentos foram recortados com navalha descartável para precisar uniformemente a superfície a ser estudada. Em seguida, eles foram desidratados na série álcoois-xilol, incluídos em parafina a vácuo e cortes de 4ìm foram obtidos em micrótomo rotativo. Finalmente os cortes foram processados rotineiramente para coloração pela hematoxilina e eosina e examinados com microscopia de óptica.

\section{RESULTADOS}

Todos os cães sobreviveram à cirurgia e ao acompanhamento pós-operatório. À relaparotomia, observou-se no Subgrupo 1A, grande quantidade de sangue e de coágulos intra-abdominais, principalmente no espaço subfrênico esquerdo, porém já não havia mais sangramento esplênico ativo. Após 28 dias, no abdome de todos os cães, observou-se pequena quantidade de sangue no espaço subfrênico esquerdo. As bordas da ferida esplênica estavam unidas em todos os animais, inclusive naqueles com apenas cinco dias de acompanhamento (Subgrupo 1A). Foram encontradas aderências de omento e cólon ao baço com maior intensidade no Subgrupo $1 B$ e no Grupo 3. Não foram observados sinais de infecção esplênica, abdominal ou sistêmica.

Nos grupos 2 e 3 não se encontrou o fio de categute que suturou a lesão esplênica. Em todos os animais a cicatriz do baço tinha bom aspecto. No Grupo 3, o omento maior permanecia dentro da ferida aderido ao parênquima esplênico. (Figura 1a)

À microscopia, no Subgrupo 1A, observou-se áreas de necrose e hemorragia recente no local da incisão. Depósitos de fibrina e hemossiderina associados preenchiam o espaço entre as bordas da lesão. No Subgrupo 1B, havia hemorragia e fibrose intensa na área da lesão, além de folículos linfáticos hiperplásicos e filetes nervosos espessos, às vezes com aspecto de neuroma. $\mathrm{O}$ omento encontrava-se aderido à cápsula em dois cães desse subgrupo. Em um animal, havia grande área de necrose em uma das bordas da incisão.

No Grupo 2, encontrou-se tecido fibroso espesso unindo as bordas da lesão, com área de hemorragia na intimidade do tecido cicatricial. Em dois cães havia focos de necrose do parênquima esplênico.

No grupo 3, os fenômenos cicatriciais foram mais intensos do que nos outros dois grupos, incluindo fibrose com neoformação vascular aparentemente maior e focos de reação gigantocelular na cicatriz. Em três cães desse grupo observou-se tecido omental, circundado por tecido fibroso cicatricial, aderido ao parênquima (Figura 1b), nos outros dois animais o omento encontrava-se apenas aderido à cápsula esplênica. Ao contrário dos Grupos 1 e 2 , não foi vista área de necrose nos cães do Grupo 3.
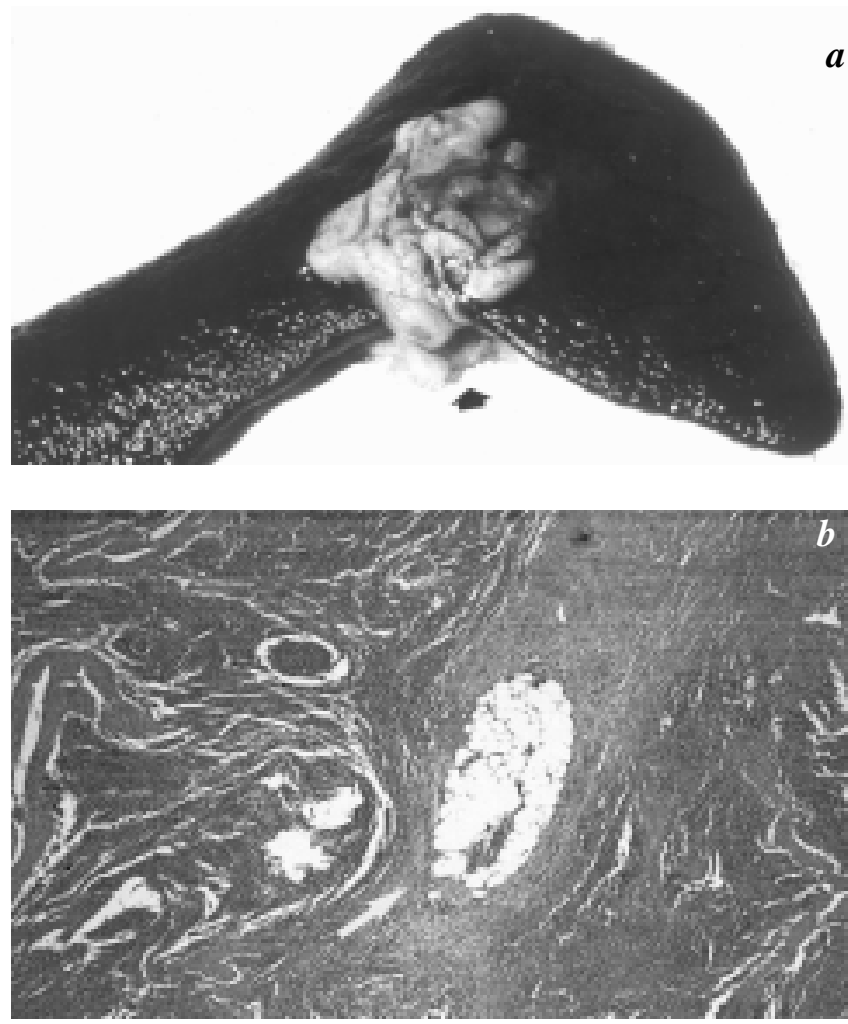

Figura 1 - Baço submetido a corte e omentoplastia (Grupo 3). Retirado no $28^{\circ}$ dia pós-operatório:

a) Observar tecido omental aderido ao baço (seta); b) Corte histológico mostrando tecido omental (seta) envolvido por conjuntivo fibroso formando septo no parênquima esplênico (hematoxilina e eosina, 80x). 


\section{DISCUSSÃo}

O ferimento esplênico, apesar de suas dimensões e secção transversal do parênquima, não foi suficiente para causar morte por hemorragia, mesmo nos cães com ferida não tratada (Grupo 1). Esse dado reforça a eficácia do tratamento não-operatório de lesões esplênicas, particularmente, aquelas de grau I e II pela classificação de Buntain ${ }^{5,9}$.

Não houve diferença entre os dois tipos de reparo esplênicos, com e sem omentoplastia, contudo, o uso do omento maior facilitou a sutura. Ambas as esplenorrafias coibiram o sangramento esplênico de imediato, ao contrário do ocorrido nos animais do Grupo 1, cujo sangramento foi considerável e persistiu até o fechamento da cavidade abdominal. Com base nos achados após cinco dias (Subgrupo 1A), percebeu-se a volumosa quantidade de sangue perdida. Mesmo assim, os animais não ficaram prostrados e mantiveram o comportamento dentro das gaiolas similar aos animais dos Grupos 2 e 3 .

A presença do omento dentro do parênquima esplênico de três animais do Grupo 3, mesmo após 28 dias, sugere que o baço possa ter englobado parte dessa estrutura durante o processo cicatricial. Esse fenômeno foi diferente do observado em trabalho prévio com o fígado, ${ }^{1}$ em que se observou a expulsão do tecido omental introduzido dentro do fígado. Cabe, entretanto ressaltar que em dois animais desse grupo o omento havia saído do parênquima do baço permanecendo apenas aderido à sua cápsula. É provável que a reação esplênica ao tecido omental seja responsável, em parte, pela fibrose com neoformação vascular, que foi maior no grupo em que a esplenorrafia foi realizada com auxílio dessa estrutura.

Não foi possível verificar se os vasos sangüíneos do parênquima, que foram seccionados, readquiriram sua continuidade. Em um cão do Subgrupo 1B foi evidenciada, tanto macro quanto microscopicamente, a presença de grande área de necrose, distalmente à incisão, devido ao não restabelecimento de irrigação para aquela região. Esse achado não ocorreu nos outros cães desse grupo. Focos de necrose foram encontrados também em quatro cães do Grupo 1A e em dois cães do Grupo 2. Por outro lado, a ausência necrose nos cães do Grupo 3 sugere que o tecido omental possa ter auxiliado no restabelecimento da irrigação distal do órgão, fenômeno esse que merece estudos futuros.

Concluindo, a omentoplastia facilitou o reparo de lesões esplênicas em cães e permitiu sua hemostasia, porém os resultados finais não diferiram dos obtidos com a sutura contínua ou com o acompanhamento sem sutura esplênica. Ao contrário da literatura, que indica tratamento cirúrgico sobre o baço em toda lesão esplênica penetrante, ${ }^{3}$ o presente trabalho mostrou que, experimentalmente, esse órgão é capaz de coibir o sangramento espontaneamente e recuperar sua integridade sem a intervenção operatória. A permanência do omento dentro do parênquima esplênico, após completar-se a cicatrização, indica que o baço pode incorporar estruturas em seu interior, durante o processo de cura.

\begin{abstract}
Background: The treatment morbimortality of splenic trauma is related to the size of the lesion and to the surgeon experience. Our purpose was to verify the splenic recovery after conservative methods of treating incisional splenic lesions in dog. Methods: Twenty male mongrel dogs weighing between 7 and $12 \mathrm{~kg}$ were submitted to a $3 \mathrm{~cm}$ deep and $5 \mathrm{~cm}$ long longitudinal incisions of the spleen under sodium pentabarbital anesthesia. The dogs were randomly divided into three groups: Group 1 $(n=10)$-without repair (control); Group $2(n=5)$ - only splenic suture; Group $3(n=5)$ - splenic suture and omentoplasty. Repairs were performed by using running suture with 5-0 chromic catgut thread. The animals of Group 1 were followed during five $(n=5)$ and $28(n=5)$ days. The dogs of groups 2 and 3 were followed during 28 days. Results: All animals survived uneventfully during the follow-up period, even those without treatment. The macroscopic splenic aspect did not differ among the groups. The microscopic assessment showed remnant omental tissue inside the splenic healing in Group 3. Conclusion: Severe incisional splenic wound in the dog may be treated conservatively. In case of operation, wound suture with or without omentoplasty is enough.
\end{abstract}

Key words: Spleen/injuries; Splenectomy; Splenectomy/methods; Wounds and injuries.

\section{REFERÊNCIAS}

1. Petroianu A, Trapiello Neto VT, Esquerdo CRM, et al. - Efeito da secção hepática parcial e omentoplastia na regeneração hepática de cão. Rev Col Bras Cir, 1999, 26(3):181-184.

2. Cardoso JB, Scarpelini S, et al - "Esplenorrafias". In Andy Petroianu - O baço. $1^{a}$ Edição. São Paulo. CLR Balieiro Editores, 2003, pp. 322-327.

3. American College of Surgeons - Committee of trauma. Advanced trauma life support. Instructor Manual. $6^{\text {th }} \mathrm{ed}, 1997$.

4. Andrade JI - "Atendimento inicial ao traumatizado". In Rocha PRS, Andrade JI, Souza C - Abdômen Agudo - Diagnóstico e tratamento. $2^{\circ}$ Edição. Rio de Janeiro. MEDSI, 1993, pp.517526.
5. Resende V - "Tratamento conservador do baço". In Petroianu A - O baço. $1^{\text {a }}$ Edição. São Paulo. CLR Balieiro Editores, 2003, pp. 265-269.

6. Resende V, Petroianu A - Esplenectomia subtotal no tratamento do trauma esplênico grave. Rev Col Bras Cir, 1997, 24(4):205208.

7. Feliciano DV, Bitondo CG, Mattox KL, et al. - A four-year experience with splenectomy versus splenorrhaphy. Ann Surg, 1985, 201(5):568-575.

8. Downey EC, Shackford SR, Fridlund PH, et al. - Long-term depressed immune function in patients splenectomized for trauma. J Trauma, 1987, 27(6):661-664.

9. Acetta P, Acetta I - "Cirurgia conservadora do baço". In Petroianu A - O baço. $1^{\text {a }}$ Edição. São Paulo. CLR Balieiro Editores, 2003, pp. 340-351. 
10. Petroianu A, Silva RG, Simal CJ, et al. - Late postoperative follow-up of patients submitted to subtotal splenectomy. Am Surg, 1997, 63(8):735-740.

11. Accetta $\mathrm{P}$ - Tratamento cirúrgico conservador no trauma esplênico. Dissertação. Niterói. Universidade Federal Fluminense, 1993, $94 \mathrm{p}$.

12. Accetta P, Accetta I, Perrotta U - Segmentação esplênica. Estudo anátomo-radiológico. Rev Bras Cir, 1983, 73(4):211-218.

13. Petroianu A, Silva RTF, Parreira LM, et al. - Alterações morfológicas do fígado após secção hepática parcial e omentoplastia. Rev Col Bras Cir, 1998, 25(1):15-17.
14. Petroianu A - Aspectos éticos na pesquisa em animais. Acta Cir Bras, 1996, 11(3):157-164.

Endereço para correspondência:

Prof. Andy Petroianu

Avenida Afonso Pena, 1626 - apto. 1901

30130-005 Belo Horizonte, MG

Fone / FAX: (31) 3274-7744 ou 8884-9192 (telefone móvel)

E-mail: petroian@medicina.ufmg.br 